Article

\title{
Applying Spatial Mapping of Remotely Sensed Data to Valuation of Coastal Ecosystem Services in the Gulf of Mexico
}

\author{
Valerie Seidel *, Daniel Dourte and Craig Diamond \\ The Balmoral Group, Winter Park, FL 32789, USA; ddourte@balmoralgroup.us (D.D.); \\ cdiamond@balmoralgroup.us (C.D.) \\ * Correspondence: vseidel@balmoralgroup.us; Tel.: +01-407-629-2185
}

Received: 26 April 2019; Accepted: 30 May 2019; Published: 5 June 2019

check for updates

\begin{abstract}
Spatial mapping of remote sensing data tends to be used less when valuing coastal ecosystem services than in other ecosystems. This research project aimed to understand obstacles to the use of remote sensing data in coastal ecosystem valuations, and to educate coastal stakeholders on potential remote sensing data sources and techniques. A workshop program identified important barriers to the adoption of remote sensing data: perceived gaps in spatial and temporal scale, uncertainty about confidence intervals and precision of remote sensing data, and linkages between coastal ecosystem services and values. Case studies that demonstrated the state of the science were used to show methods to overcome the barriers. The case studies demonstrate multiple approaches to valuation that have been used successfully in coastal projects, and validate that spatial mapping of remote sensing data may fill critical gaps, such as cost-effectively generating calibrated historical data.
\end{abstract}

Keywords: coastal ecosystems; remote sensing; ecosystem services valuation

\section{Introduction}

Ecosystem services valuation studies tend to be very local in scope, as summarized eloquently by Barbier (2012) [1]: the value of selected species impacted in the Greater Everglades restoration [2], the recreation value of coastal marshes in Saginaw Bay [3], etc. Policymakers frequently need to scale up to a broader geography for decision-making purposes. Spatial mapping of satellite data (hereafter, Earth Observations, or "EO" data), and other remotely sensed data, provides a convenient vehicle for extrapolating the right valuation data to a desired geographic or temporal scale. The research objective for this project was to identify barriers to the greater use of EO data in coastal ecosystem valuation, and potential solutions to improve the use of EO data.

Over the past two decades, remotely sensed data have been the standard bearer for many data sources underpinning ecosystem services assessments. Land use and land cover data products derived from aerial photography are common uses of remotely sensed data in valuations of social and environmental benefits from natural resources. Ecosystem services mapping presents its own challenges, as noted by Drakou (2015) [4] and others [5].

Coastal ecosystems, however, have been less well represented in the use of remotely sensed data. Coastal ecosystems do not fall easily into the land use nor marine categories for which many if not most ecosystem services assessments have been completed using remote sensing. A review of The Economics of Ecosystems and Biodiversity database ("TEEB") of ecosystem services values reveals that 312 of the 1310 entries address nine coastal ecosystems, 119 of which are focused on just four ecosystem services (food, climate, recreation, and extreme events) [6]. As Drakou [7] notes, ecosystems and their services may occur in locations separated by significant distances at the coast. 
A 2018 review of coastal ecosystems references in TEEB finds that sea-grass beds are the least considered ecosystems, while tourism and recreation services are the most common ecosystem service considered [8]. Ecosystem services particularly important to coastal resource managers, like storm protection and erosion reduction, have not been as frequently valued in the literature due to the sophisticated hydrodynamic models required to estimate the impacts of different coastal ecosystems on flooding and land loss/gain [9]. Meanwhile, resource managers, whether in administering estuarine research and preservation, land management in coastal communities, or habitat restoration in coastal watersheds, spend precious financial and staff resources collecting data to estimate coastal ecosystem condition and to monitor trends in coastal ecosystems as part of ongoing project work.

Based on discussion with coastal managers of the types of data being collected, at least some of the data collection effort currently taking place could potentially be replaced with EO data sources. The research team proposed a series of workshops in Gulf Coast states to advance the use of Earth observations for valuing ecosystem services and to define practical means to incorporate these values into resource planning and decision making in the coastal environment.

Partners in the workshops would include public and private sector stakeholders that share the common goal of improving the resilience of coastal infrastructure and natural systems. Coastal infrastructure, including (constructed) living shorelines and natural barrier islands, dunes, shellfish beds, and coastal wetlands, have been identified generally as having significant potential to improve community resilience against storms and sea level rise, rebuild coastal ecosystems and increase the ecological benefits and services that contribute to coastal economies. However, specific economic measures of such benefits are either lacking or are insufficiently quantified to provide practical information to decision makers. This is particularly the case where such ecological services compete for weight or consideration against more broadly understood goods and services recognized by markets and the various economic measures historically used by decision makers.

The workshops would be designed specifically to evaluate key elements of implementing ecosystems services into the resource planning processes, such as the following:

- What data sources, including Earth observations, are needed to improve the approaches for valuing coastal ecosystem services relating to resilience?

- What valuation techniques best translate quantified ecosystems services defined for the Gulf Coast area?

- To what degree do resource managers currently use the values of ecosystems services in decision making?

- What institutional and informational barriers exist that constrain the application of ecosystem services within decision making related to planning and management of coastal resources?

- What steps need to be undertaken to accelerate the adoption of ecosystem valuation and elevate its impact on decision making?

The aim of the workshop series was to include guidance to NASA and other Federal agencies on the use of earth observations to inform ecosystems valuation within a regional resource- the Gulf of Mexico-with numerous interacting agencies, Federal and state.

\section{Methods}

Via a series of workshops with coastal resource managers, we set out to investigate the reasons for the under-utilization of EO data for coastal ecosystems valuation. The workshops were prefaced with a literature review, telephone interviews and surveys to understand the familiarity with EO data for coastal ecosystems, and barriers to its application. The workshop series was intended to be an exercise in iterative learning so that each session built on its predecessors in terms of constructing a knowledge base about the application of ecosystems valuation in theory and practice, as related to local and Federal agency resource planning and coordination. 


\section{Workshop Participants, Locations, Contents}

Based on feedback from the telephone interviews conducted during the first six months of the project, workshops were scheduled for locations in each of the five Gulf of Mexico States. Venues were selected from public facilities used regularly by the National Estuarine Research Reserves (NERRs), National Estuary Programs (NEPs), and their stakeholders (like the Harte Research Institute at Texas A\&M). Target attendees were identified through existing coastal information networks with the assistance of key stakeholders in each region. Resource managers from federal, state and local governments, coastal researchers, and not-for-profit groups focused on coastal conservation, science, and management were identified and invited to participate in an online survey, telephone interview, and workshop registration. Five workshops were delivered, one in each of the five Gulf Coast states over a 7-month period during the 18-month project.

Prior to each workshop, a custom survey was drafted to reflect the specific issues to each region and refine the specificity of issues toward the project objectives. The results of each survey were used to adjust the agenda to the user audience, and specifically to their identified level of familiarity with remote sensing tools, datasets and application to coastal ecosystem services.

Workshop content was prepared based on literature review, extensive interviews of experts and field practitioners, and steering committee members. A database of about 130 peer-reviewed publications or white papers related to spatial ecosystem services was assembled and utilized to guide workshop content development. Publications included those about research in remote sensing for modeling ecosystem services [10] and those about applications of ecosystem service information for management or planning improvements, particularly in coastal areas [11-13]. Additionally, numerous publicly available ecosystem service models were evaluated, and the most relevant EO data access and analysis portals were assembled for inclusion in the training portions of the workshops.

Evolving research of ecosystem services assessments has identified that beyond the challenges of logistics and scientific complexity, numerous social factors, including "management regimes, power relationships, skills, and values" [14], can influence approaches to ecosystem services. In response, participatory methodologies have emerged to capture the human aspects of interdependence and uncertainty in ecosystem services assessments $[15,16]$. One area of interest for the workshops was an understanding of the factors beyond scientific complexity that may influence current practice. In several of the workshops, a local expert was invited to review a local case study in ecosystem services, and describe the application of remotely sensed data to the region.

\section{Workshop Results}

Each workshop was near capacity and attracted between 25 and 35 attendees with varying levels of background in EO data, ecosystems services and valuation methods. Generally speaking, our research found that coastal managers and researchers in the Gulf States are not commonly employing EO data to value ecosystem services. Figure 1 reflects workshop participant responses regarding their pre-workshop use of ecosystem services quantities estimates. 


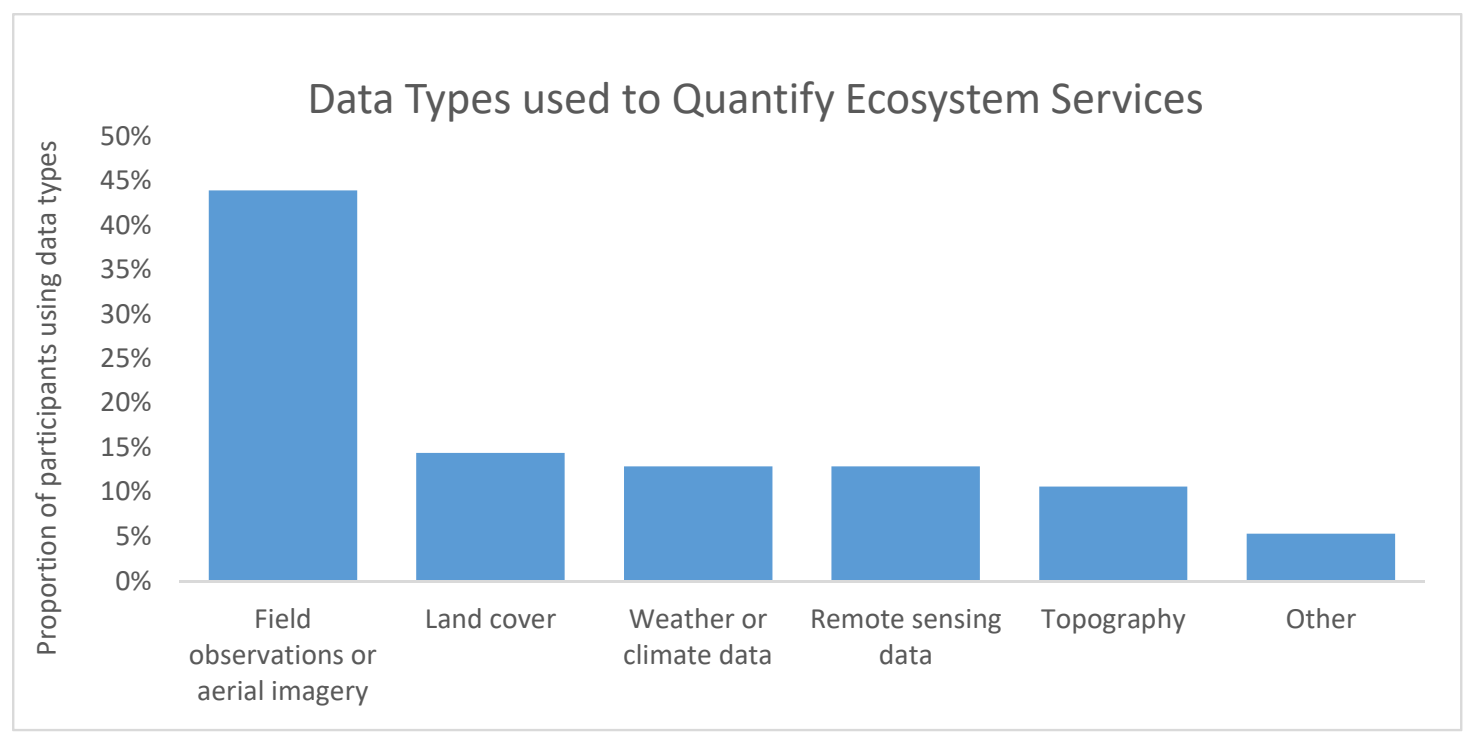

Figure 1. Workshop participant responses regarding current practice.

In a broader context, coastal managers tend not to attempt valuation of ecosystem services in general, relying instead on more traditional areal extent measures to quantify ecosystems (i.e., hectares of seagrass, acres of emergent marsh, etc.). Most practitioners are regularly collecting data on coastal ecosystems; some have collected data on ecosystem services; few have attempted to value ecosystem services, whether the value in question is economic or some other measure of societal benefit. Figure 2 summarizes the stated purpose for existing efforts to quantify ecosystem services, as reported by workshop participants.

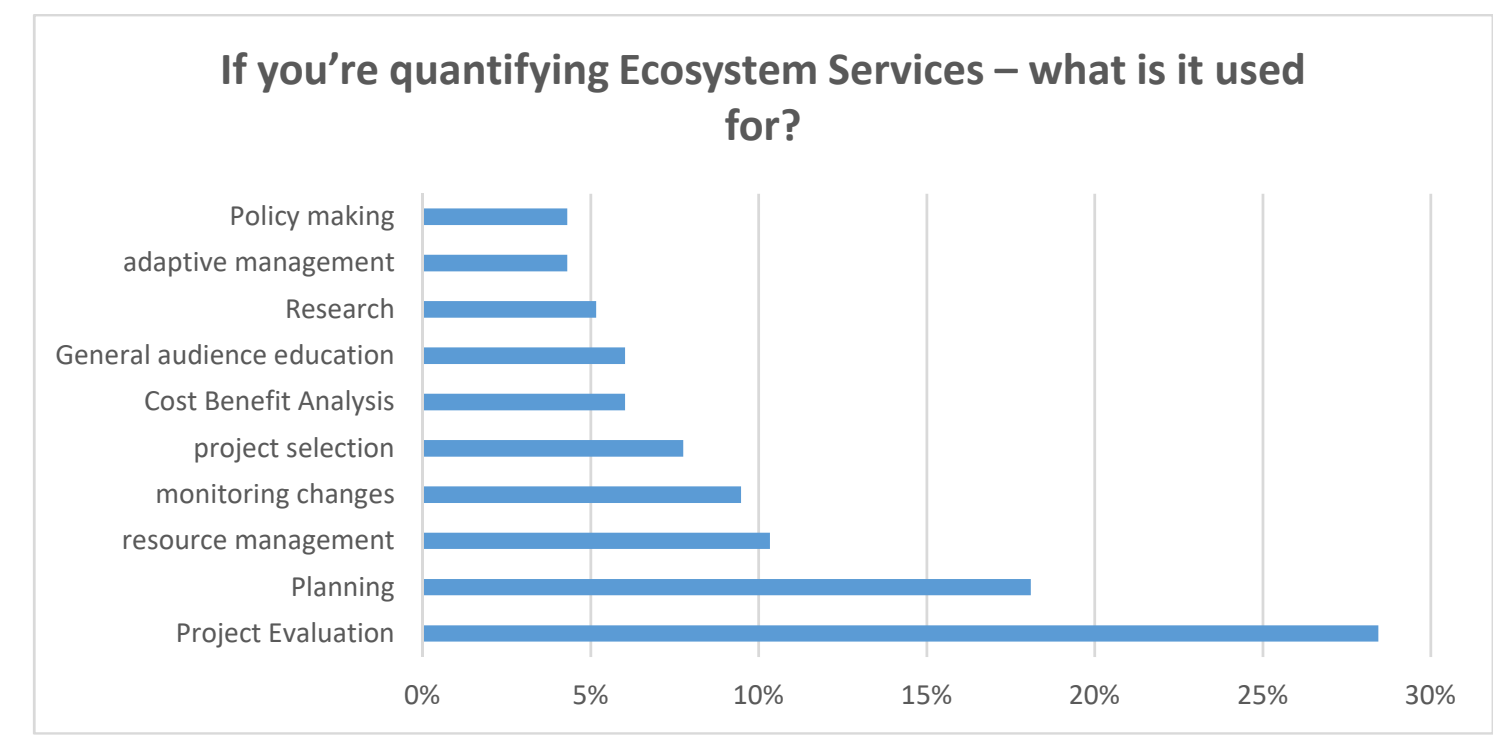

Figure 2. Workshop participant responses regarding uses of ecosystem services quantities.

General awareness of EO data that could be productively used in coastal ecosystem valuation was low, but varied significantly between states. The critical finding, beyond awareness, relates more to the linkage between remote sensing data and locally collected data.

Interpolation of multiple scales of spatial and/or temporal resolution data was not routinely considered, and as a result practitioners tended to dismiss EO data for detailed analysis. Similarly, overlaying or merging other datasets that could create the finer level of information was generally dismissed. Using coastal or local case studies increased awareness of the process, and reduced resistance 
to lower resolution datasets. The workshops used specific case studies that improved the state of the science as examples, including those described in the next section.

While the experience of the practitioners attending the workshops was varied, there remained a clear interest in expanding the use of EO data for a range of management needs (within their constraints of time and priorities). The use of $\mathrm{EO}$ for ecosystems valuation was generally considered important as, in their view, valuation outcomes are often critical in discussions with policy and decision makers. The issue for many was ensuring a comfort level with valuation, quantifying uncertainty, and understanding practical applications. Figure 3 summarizes the responses to which ecosystems services matter most in coastal managers' regular work activities.

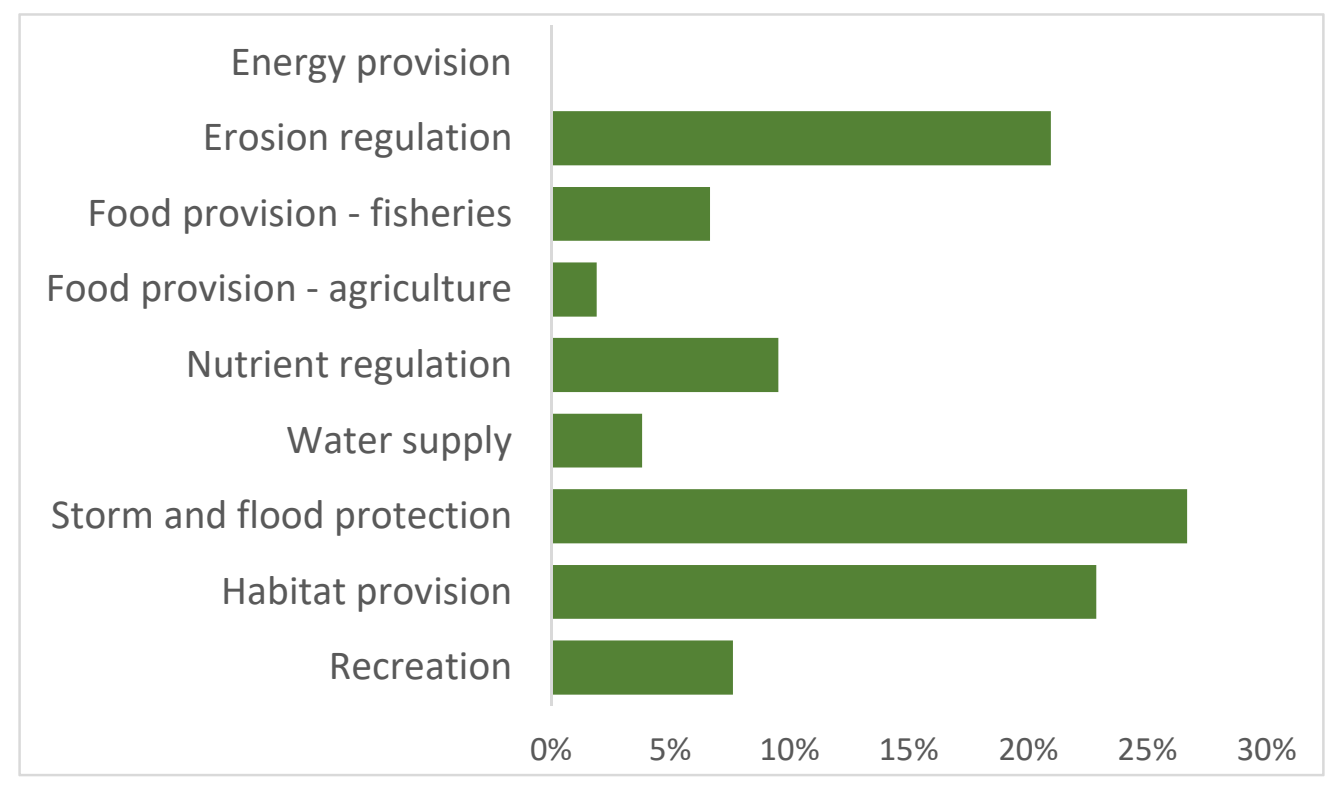

Figure 3. Workshop responses to which ecosystem services matter most in participants' work.

The case study examples in the next section demonstrate varied applications of earth observation data to improve coastal ecosystem management.

\section{Case Studies in Using Earth Observations for Coastal Ecosystem Valuation}

\subsection{Evaluating Costs and Benefits of Coastal Resiliency Strategies}

The State of Florida recognized that increasing coastal hazards would require consideration of new planning strategies for local governments. Required by statute to prepare "Comprehensive Plans", local governments establish rules regarding development, construction, and levels of municipal services that are obligated to local residents. The State contracted The Balmoral Group to perform a cost-benefit analysis of coastal resiliency strategies for consideration in Comprehensive Plan updates, including transfers of development rights, zoning changes, planned retreat, and armoring (sea walls). The State's interest was two-fold: (1) identifying the level of incentives required to motivate responsible development without a command regulation approach and (2) offering Comprehensive Plan language for counties to use in addressing development or redevelopment in hazardous coastal areas.

Florida's population and landscape are diverse, and two counties volunteered as pilots for the analysis-Martin County, which is Atlantic Ocean-facing, and home to a higher income, relatively less diverse population of about 160,000; and Okaloosa County, which resides on the Gulf of Mexico, houses the largest military base in the U.S., and partly because of the large base, includes more undeveloped land for its 200,000 residents. All properties seaward of the Coastal High Hazard Area were included in the analysis. Estimating realistic costs and benefits to identify thresholds at which incentives would change behavior required assessing conditions at the site level: economics, wave energy, environmental 
factors, and others. With thousands of public and private properties in play, remote sensing data were used to calculate specific values at the property level in a Geographic Information System, or GIS.

Both cost and benefit factors were assessed in GIS at the property level, including acquisition costs, construction costs for armoring or demolition, amenity values, avoided costs, and foregone revenues. Publicly available parcel data were obtained from property appraisers and overlaid with high resolution aerial photography, land use/land cover data for wetlands delineation and permanently preserved lands, and beach zones. Remote sensing data played a key role in efficiently assigning values. For example, armoring costs were estimated by linear foot depending on the wave energy with decision rules developed with coastal engineers; values ranged from $\$ 5250$ to $\$ 10,800$ per meter (in 2019 dollars). Ecological values for beach habitat were estimated based on public values for ecological protection (of habitat and sea turtle nesting sites) of $\$ 11 /$ resident and applied evenly to waterfront parcels adjacent to critical beach areas [17]. Public values for recreational access to the beach were calculated using Willingness to Pay (WTP) values of \$67-183/visit and beach visitor data; and values for wetland preservation, where wetlands may allow seagrass migration to occur, ranged from $\$ 37,000$ to $\$ 79,000$, with an inflation adjusted mean of $\$ 53,300 /$ ha [18]. The resulting values contributed to a comprehensive evaluation of feasible coastal resiliency strategies; ultimately, the analysis found that all strategies were feasible in some areas under current conditions, but the results were place-specific and changed considerably under alternative future climate scenarios.

The Coastal Resiliency Strategies example provides a solid case of using remote sensing data to estimate values with spatially distinct variation across large areas and subjects. Gathering site-level detail through field work would have proven too expensive and time-consuming for an economic analysis of cost and feasibility. Combining engineering (wave energy, armoring costs) and scientific input (critical erosion areas, sea turtle nesting sites, and wetland delineation) with economic values, calculations across thousands of individual sites were completed rapidly and with precision. It is likely that this sort of analysis would have previously been addressed through county-level averages, potentially painting a very different picture of which strategies would be feasible for a given neighborhood, street or community. The values can readily be updated, using annually updated datasets.

\subsection{Restore the Balance: TBEP Applies Remote Sensing Data to Understand Habitat Mosaic and Ecosystem Services}

The Tampa Bay Estuary Program (TBEP) recognized the need for a habitat mosaic approach. Upstream freshwater wetlands were critical to certain estuarine species lifecycles, and diminishing populations of these species was causing economic consequences to tourism and recreational fishing. Understanding that different basins/hydrologic units in the watershed had changed in different ways, TBEP undertook analysis to assess trends from pre-urbanization to recent conditions.

For the region, the earliest data available dated to military flight aerial photography from the early 1950s. Digitized historical aerials, national wetland inventory data and national hydrography data [19] were combined in GIS to evaluate trends in wetland composition and to build Landscape Development Intensity (LDI) values for 1952 and 2007, based on the work of Brown and Vivas [20]. Changes in wetlands, by basin and type, were quantified, recognizing that a greater percentage loss of specific types of wetlands at key locations within a particular basin or hydrologic unit may mean substantial changes to ecosystem dynamics.

(Note: LDI values are expressed in units of emergy or solar emjoule (seJ/ha/year). In this case, the output of manual inspections of surrounding land use, wetland condition and other factors in Florida's Uniform Mitigation Assessment Method was compared to predictions by LDI.)

LDI values were estimated in GIS on a $10 \mathrm{~m} \times 10 \mathrm{~m}$ grid. Conditional assessments were performed via site visits to assess condition and vulnerability, understand types of change, and calibrate LDI measurements. The conditional assessments considered location and landscape support, water environment, and community structure; the LDI predicted observed field conditions reasonably well, with an $\mathrm{R}^{2}$ of 0.69 . Based on the findings of 37 site visits, the LDI calculations were calibrated and 
completed for the remaining roughly 5200 square kilometer watershed at 0.2 ha accuracy. The data were then used to estimate coastal ecosystem services, including relative nutrient reduction and regulation, water supply, and flood attenuation. Figure 4 shows example maps reflecting spatial mapping of projected LDI based on future land use plans in the left panel, while the right panel shows wetland connectivity.
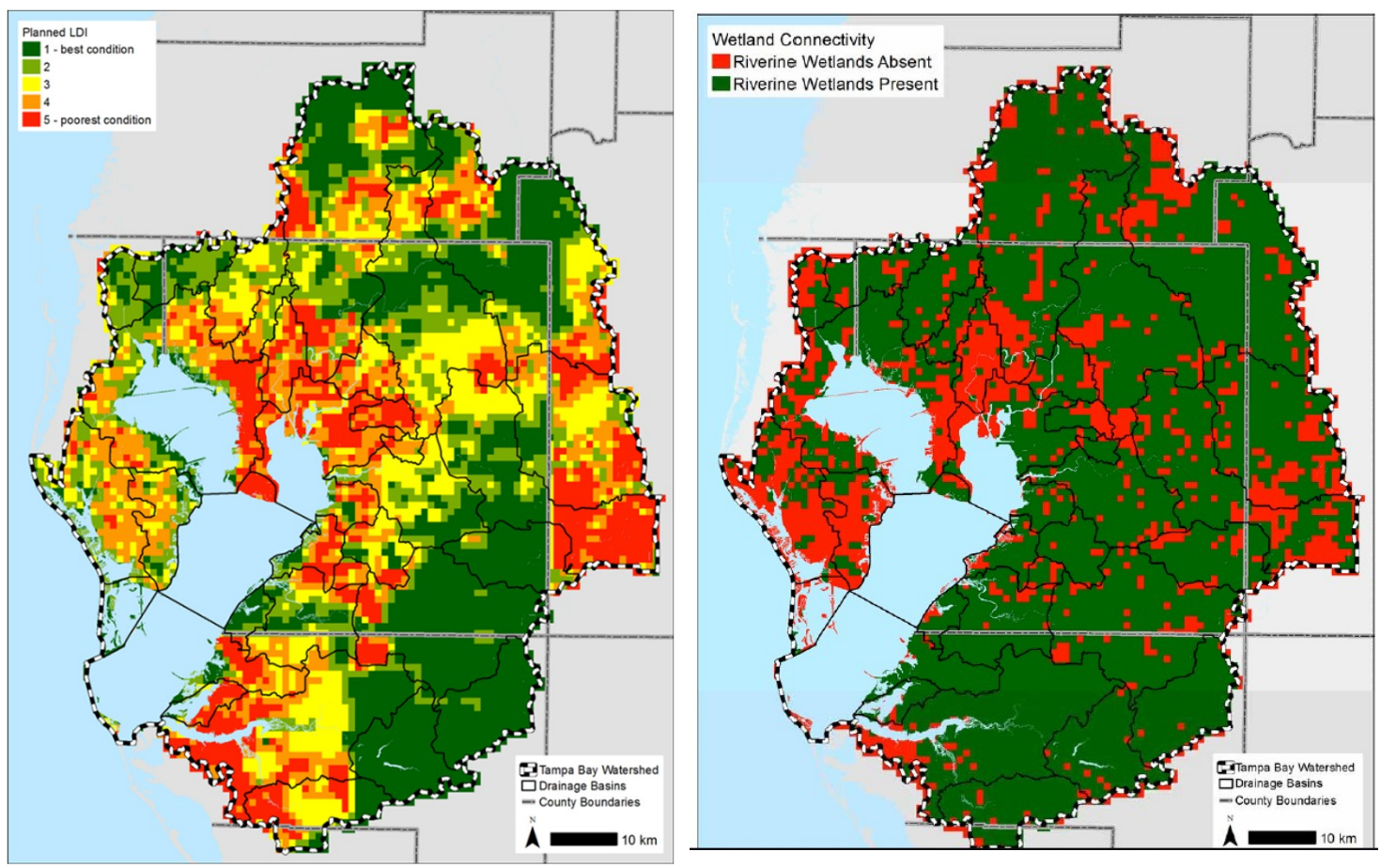

Figure 4. Example maps, projected landscape development intensity, and wetland connectivity, Tampa Bay watershed. (a) Planned LDI, representing economic vulnerability due to pending development (green = least vulnerable, red = most), (b) Wetland connectivity, showing presence or absence of riverine wetlands (green $=$ present, red $=$ absent).

With an overall objective of setting wetland-level priorities of restoration, preservation or mitigation, several additional measures were generated, including wetland change (by type and function), conditional assessment, hydrologic connectivity to bay, and economic vulnerability, based on planned development in the area. Regionally, the information became part of the restoration targets for the update to TBEP's Comprehensive Conservation and Management Plan. Permitting agencies adopted the historical condition and the resulting overall prioritization plan into their rules; permitting decisions reference the output to achieve regional goals one wetland at a time.

With advances in the temporal and spatial resolution of remote sensing data, the data were recently updated using the Integrated Valuation of Ecosystem Services and Tradeoffs model, or InVEST, to estimate ecosystem services values [21]. TBEP project data, which included remote sensing data for elevation (USGS Digital Elevation Model), land use and land cover (LULC), rainfall (PRISM), and watershed boundaries (USGS), were used as InVEST inputs; biophysical factors linking land cover to soil and vegetation parameters were added to finalize calculations. InVEST estimated nitrogen retention in $\mathrm{kg} /$ year in the TBEP watershed by basin, and relative recreational opportunity values by basin. The process required less than two days' effort, versus more than a year to build the original dataset. From a budgetary perspective, this is an investment of potentially less than $\$ 1000$ versus nearly $\$ 100,000$. Once the model is built, InVEST estimates can be updated with minimal effort on a regular basis, using the most recent remote sensing data. 
The InVEST application, while helpful in assessing relative values, does not provide an actual estimate for the economic value of ecosystem services. The nutrient regulation model provides relative nitrogen retention by basin, which can be converted to economic equivalence using published values of $\$ 140 / \mathrm{kg}$ [22]. The recreation model provides an estimate of the relative recreational opportunity value, with estimates by basin/hydrologic unit ranging from a low of 4 to a high of 1937, but these values are not readily convertible to monetized estimates. Additional effort would be required to convert the relative values for recreation to economic benefits, a task likely to be beyond the budget and expertise of most coastal managers. The lack of a more complete valuation demonstrates one drawback of the InVEST approach, and is consistent with current practice of quantifying coastal ecosystem services in ways that avoid economic valuation. While not addressed in the TBEP project directly, literature on benefit-relevant indicators offers a path for translating the value estimates from the project into monetized values; see, for example, Olander [23]. From a prioritization perspective, the relative value is still helpful.

The TBEP project offers an additional example of using remote sensing data, coupled and calibrated with limited field observations to produce ecosystem services valuation information that is directly applicable to coastal management actions.

\subsection{Mangrove Heart Attack}

Charlotte Harbor National Estuary Program (CHNEP) had large saltwater mangrove mortality areas with adjacent areas showing stress and potential expansion of the die-off to thousands of acres; management did not know the cause, but speculated that development was impacting mangrove health. Using published values for storm protection services provided by mangroves of up to \$3116/ha [24], CHNEP's mangrove area potentially offers $\$ 80$ million in protection from extreme events, while past studies have found that mature, healthy mangrove in the CHNEP provide $\$ 75,300 /$ ha in annual fisheries production alone. With $\sim 700$ square $\mathrm{km}$ of area, partitioning the management approach to fund appropriate mitigation measures was no small feat. In attempting to tackle the issue, staff identified published methods to use Landsat 8 color bands/normalized difference vegetation index (NDVI) to identify mangrove health in remote locations. Using green and near-infrared bands of Landsat 8 data, as per Giri et al. 2015 [25], varying conditions of mangrove could be assessed.

Staff started by comparing the Green Normalized Difference Vegetation Index data for the mangrove areas from 1985 and 2015; using the NDVI Green (NDVIg) values, natural breaks found intervals of greenness beginning at 0.9554 , and gradually increasing to 0.9751 . Only those which showed low NDVI green (less than 0.9554), and had declined, were included in the study. The pixel size based on the available data was $\frac{1}{4}$ acre; at the scale of the NEP, this was a useful starting point for assessing condition. Site visits were carried out to collect field samples and calibrate data at 56 sites; the field work found that the NDVI correctly evaluated the condition with 75-83\% accuracy, which was more or at least equivalent to the official data that would otherwise have been used for land cover assessment (official meaning that prepared by South Florida Water Management District, or SFWMD) [26]. In total, 21,850 acres of condition-classified mangrove was mapped.

Where condition was poor, red and orange coding was used to flag areas, while magenta was used to highlight areas with low and declining condition. Figure 5 shows a section of North Captiva Island after processing. The bright colors augmented rapid review of the extensive forests throughout the study area. Many of the areas were remote and difficult to access, and aerials were insufficient to assess condition reliably. 


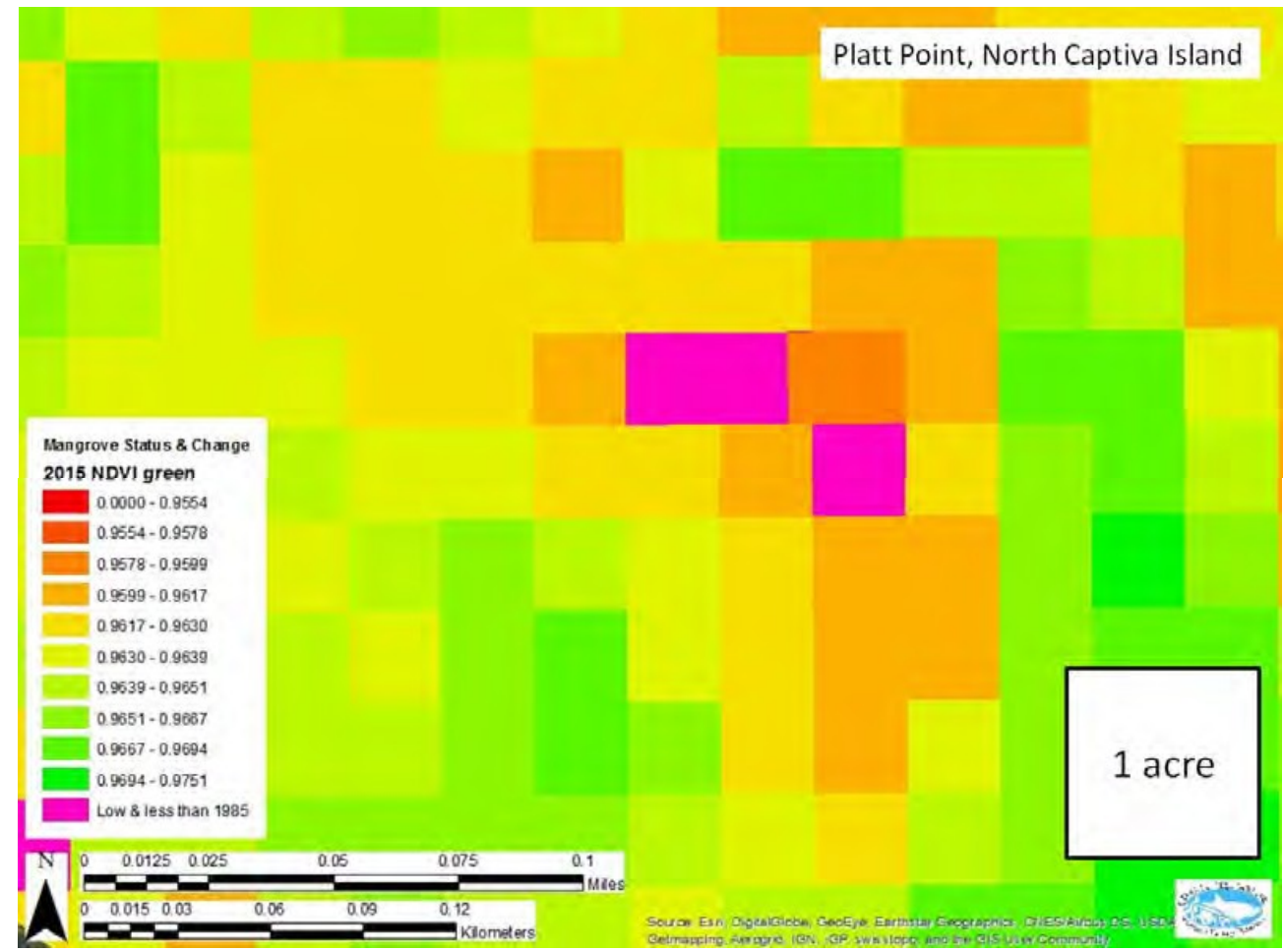

(a)

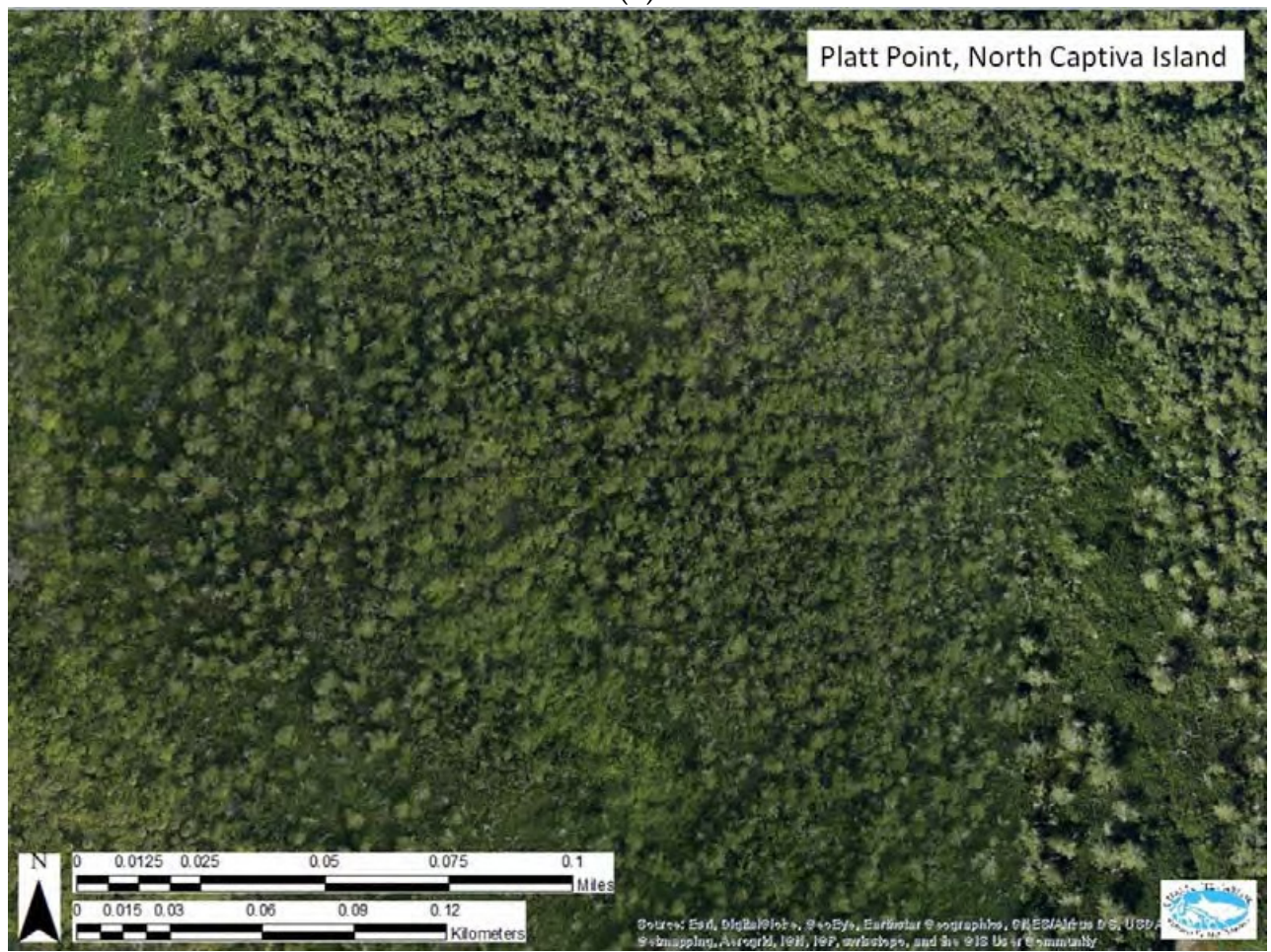

(b)

Figure 5. (a) NDVIg indicated poor condition that could not be seen from an aerial view. (b) Map: aerial view of the underlying mangrove area. Source: CHNEP [26].

At the 1:5000 scale of existing aerial photography, some decline was apparent. At 1:1000 scale, the selected pixels appeared in good condition. Upon further investigation at the 1:500 scale, which was available through Landsat 8 data, bare branches could be detected in the areas flagged as low NDVI; see Figure 6. 


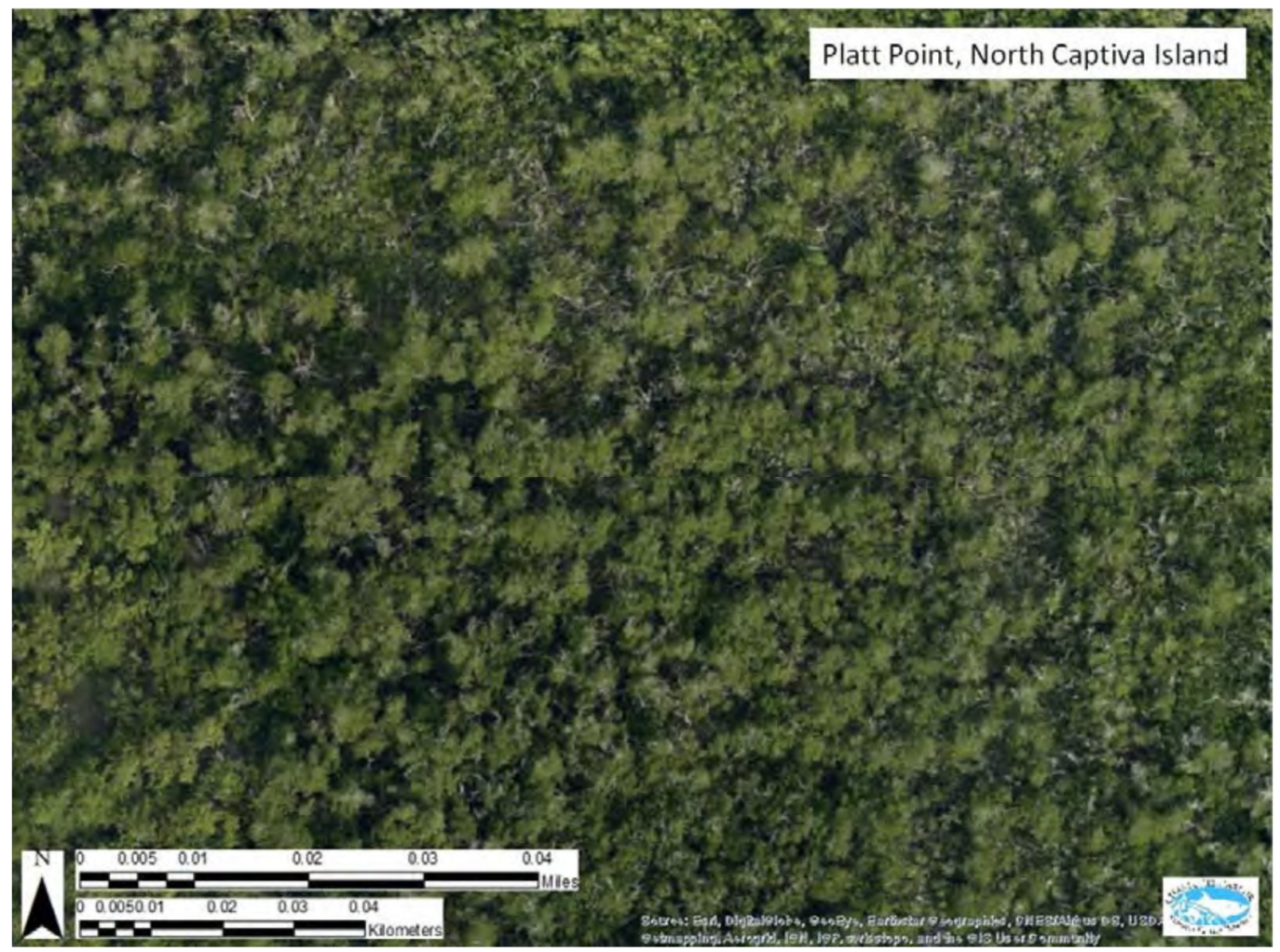

Figure 6. NDVIg indicated poor condition that could be seen at 500 scale. Source: CHNEP [26].

The authors state that "The results offer an astonishingly sensitive and detailed interpretation suggesting underlying hydrology, difficult to map from aerial photography and LiDAR digital elevation models alone ... NDVIg was sensitive enough to identify mangrove trimming and dock construction." Two hundred sites were identified through the screening for further determination. Ultimately, staff found that natural causes (sea level rise, primarily) were generating mortality at 121 sites; 13 sites had man-made stressors with no remedy available (on private land, e.g.); 90 sites were good candidates for restoration, and 3 sites had restoration already underway. With average site size, the 103 sites with restoration targeted or underway represent potential economic savings of nearly $\$ 25$ million in storm protection and $\$ 3$ million annually in fisheries production. Perhaps more significantly, recent research has found that benefits of mangrove restoration may outweigh costs by 35:1 [27].

The Mangrove Heart Attack project provides a great example of using existing data to evaluate trends, perform high-level screening, and calibrate remote sensing data to site-level inspections in a spatial mapping framework. Also, because of the ongoing collection and archiving of Landsat data, no pre-restoration monitoring is required, facilitating rapid response and potentially better resource management opportunities. The CHNEP created a perfect example of using spatial mapping to identify ecosystem services linkages, and applying remote sensing data to coastal ecosystem project decisions.

\section{Discussion and Conclusions}

A major finding of the research is the effectiveness of case studies to illustrate the accessibility and transferability of EO data to coastal resource management needs. The case studies provided real world examples of coastal applications that calibrated remote sensing data with field observations successfully. In each highlighted case, data collection through field observations would have been prohibitively expensive and time-consuming. By methodically identifying the critical factors required for the management task at hand, coastal researchers and resource managers were able to link remote sensing data to site-scale observations and calibrate remote sensing data to confidence intervals appropriate for the application. 
The outcome of the workshops was a better understanding of the requirements for building capacity in applications of Earth Observations for improved coastal management: (1) continued training opportunities in Earth Observations and models of ecosystem services, (2) emphasis on successful use-cases to demonstrate impact, and (3) improved data products specifically developed to perform well in coastal regions.

Coastal resource management frequently requires long-term monitoring, both because funders require it and to ensure methods are successful. Extrapolating or interpolating data is difficult where historical data have not been captured, and coastal environments are particularly unforgiving in this respect. The dynamics of coastal forces render data collection more expensive than on dry land, and the constantly evolving shoreline means that hindcasting is usually inappropriate. Remote sensing data may fill the gap; once calibrated, data collection pre-dating a project can be generated, with a given confidence interval.

Economic valuation of coastal ecosystems using remote sensing requires additional steps and a multi-disciplinary approach. In the case studies noted, three different approaches were used. In the first, economic values were assigned to coastal ecosystem services using the assistance of experts in non-economic disciplines to build decision rules that would provide the benefits transfer computation. In the second, InVEST models were used to provide estimates of nutrient regulation and recreation values. InVEST provides relative values, but users must assign their own estimates of economic valuation units to produce economic valuation. Finally, CHNEP summarized economic values for ecosystem services provided by mangroves, but did not attempt to quantify the change in economic values addressed by their targeted restoration efforts.

The case studies demonstrate successful applications of spatial mapping in coastal valuation environments, while the workshops reflected a broader ongoing lag in user experience and practical application to be addressed. The expanding library of successful spatial mapping applications can support future workshops, training and similar initiatives. As EO data continues to expand, there are data refinements, new algorithms, and new missions, all of which contribute to reducing some of the uncertainty expressed by the workshop participants-and support expanding use for systems monitoring, valuation and decision-making.

Remote sensing data tend to be used less when valuing coastal ecosystem services than in other ecosystems. While there are challenges to doing so, the case studies demonstrate that the gaps can be overcome. The primary obstacle perceived by coastal managers tends to relate to the geographic and temporal scale, and the case studies illustrate methods to overcome scale issues. Additional barriers include understanding the linkages between economic values and coastal ecosystem services, and how to collaborate with economists to cost-effectively bridge this gap. Finally, improved integration of and access to the plethora of remote sensing data available for use in the coastal zone may require additional training.

Author Contributions: Conceptualization, C.D.; Methodology, D.D.; Investigation, V.S.

Funding: This research was funded by NASA, Grant number 80NSSC18K0083.

Acknowledgments: The authors wish to recognize anonymous reviewers, whose comments improved the content of this article.

Conflicts of Interest: The authors declare no conflict of interest.

\section{References}

1. Barbier, E.B. A Spatial model of coastal ecosystem services. Ecol. Econ. 2012, 78, 70-79. [CrossRef]

2. Milon, J.W.; Scrogin, D. Latent preferences and valuation of wetland ecosystem restoration. Ecol. Econ. 2006, 56, 162-175. [CrossRef]

3. Whitehead, J.; Groothuis, P.; Southwick, R.; Foster-Turley, P. Economic Values of Saginaw Bay Coastal Marshes with a Focus on Recreational Values; Michigan Department of Environmental Quality: Kalamazoo, MI, USA, 2006. 
4. Drakou, E.; Crossman, N.; Willemen, L.; Burkhard, B.; Palomo, I.; Maes, J.; Peedell, S. A visualization and data-sharing tool for ecosystem services maps: Lessons learnt, challenges, and the way forward. Ecosyst. Serv. 2015, 13, 134-140. [CrossRef]

5. Townsend, M.; Davies, K.; Hanley, N.; Hewitt, J.; Lundquist, C.; Lohrer, A. The challenge of implementing the marine ecosystem service concept. Front. Mar. Sci. 2018, 5, 1-13. [CrossRef]

6. Van der Ploeg, S.; de Groot, R.S. The TEEB Valuation Database-A Searchable Database of 1310 Estimates of Monetary Values of Ecosystem Services; Foundation for Sustainable Development: Wageningen, The Netherlands, 2010.

7. Drakou, E.; Pendleton, L.; Effron, M.; Ingram, J.; Teneva, L. When ecosystems and their services are not co-located: Oceans and coasts. ICES J. Mar. Sci. 2017, 74, 1531-1539. [CrossRef]

8. Van der Ploeg, S.; De Groot, D.; Wang, Y. The TEEB Valuation Database: Overview of Structure, Data and Results; Foundation for Sustainable Development: Wageningen, The Netherlands, 2010.

9. Barbier, E.B. Valuing Ecosystem Services for Coastal Wetland Protection and Restoration: Progress and Challenges. Resources 2013, 2, 213-230. [CrossRef]

10. Martínez-Harms, M.J.; Balvanera, P. Methods for mapping ecosystem service supply: A review. Int. J. Biodivers. Sci. Ecosyst. Serv. Manag. 2012, 8, 17-25. [CrossRef]

11. Pollack, J.B.; Yoskowitz, D.; Kim, H.C.; Montagna, P.A. Role and Value of Nitrogen Regulation Provided by Oysters (Crassostrea virginica) in the Mission-Aransas Estuary, Texas, USA. PLoS ONE 2013, 8, e65314.

12. Chung, M.G.; Kang, H.; Choi, S.U. Assessment of Coastal Ecosystem Services for Conservation Strategies in South Korea. PLoS ONE 2015, 10, e0133856. [CrossRef] [PubMed]

13. Arkema, K.K.; Verutes, G.; Bernhardt, J.R.; Clarke, C.; Rosado, S.; Canto, M.; Wood, S.A.; Ruckelshaus, M.; Rosenthal, A.; McField, M.; et al. Assessing habitat risk from human activities to inform coastal and marine spatial planning: A demonstration in Belize. Environ. Res. Lett. 2014, 9, 114016. [CrossRef]

14. Davies, K.; Fisher, K.; Dickson, M.; Thrush, S.; LeHeron, R. Improving ecosystem service frameworks to address wicked problems. J. Ecol. Soc. 2015, 20. [CrossRef]

15. Dunford, R.; Harrison, P.; Smith, A.; Dick, J.; Barton, D.N.; Martin-Lopez, B.; Kelemen, E.; Jacobs, S.; Saarikoski, H.; Turkelboom, F.; et al. Integrating methods for ecosystem service assessment: Experiences from real world situations. Ecosyst. Serv. 2018, 29, 499-514. [CrossRef]

16. Pandeya, B.; Buytaert, W.; Zulkaflie, T.; Karpouzoglou, T.; Mao, F.; Hannah, D. A comparative analysis of ecosystems services valuation approaches for application at the local scale and in data scarce regions. Ecosyst. Serv. 2016, 22, 250-259. [CrossRef]

17. Lutz, P.; Musick, J. (Eds.) The Biology of Sea Turtles; CRC Press: Boca Raton, FL, USA, 2003.

18. Milon, J.; Scrogin, D.; Weishampel, J. A Consistent Framework for Valuation of Wetland Ecosystem Services Using Discrete Choice Methods; EPA Grant Number: R831598; National Center for Environmental Economics, US Environmental Protection Agency: Washington, DC, USA, 2009.

19. United States Geological Survey, or USGS. US Geological Survey. 2008. Available online: StagedProducts/ Hydrography/NHDPlus/HU4/HighResolution/GDB/ (accessed on 31 May 2019).

20. Brown, M.T.; Vivas, M.B. Landscape Development Intensity Index. Environ. Monit. Assess. 2005, 101, $289-309$. [CrossRef] [PubMed]

21. Sharp, R.; Tallis, H.T.; Ricketts, T.; Guerry, A.D.; Wood, S.A.; Chaplin-Kramer, R.; Nelson, E.; Ennaanay, D.; Wolny, S.; Olwero, N.; et al. InVEST 3.6.0 User's Guide; The Natural Capital Project; Stanford University: Stanford, CA, USA; University of Minnesota, The Nature Conservancy, and World Wildlife Fund: Minneapolis, MN, USA, 2018.

22. Dourte, D. Water Quality Project Cost-effectiveness: Evaluation Metrics; Southwest Florida Water Management District: Brooksville, FL, USA, 2017.

23. Olander, L.P.; Johnston, R.J.; Tallis, H.; Kagan, J.; Maguire, L.A.; Polasky, S.; Urban, D.; Boyd, J.; Wainger, L.; Palmer, M.; et al. Benefit relevant indicators: Ecosystem services measures that link ecological and social outcomes. Ecol. Indic. 2018, 85, 1262-1272. [CrossRef]

24. Himes-Cornell, A.; Grose, S.O.; Pendleton, L. Mangrove Ecosystem Service Values and Methodological Approaches to Valuation: Where Do We Stand? Front. Mar. Sci. 2018, 5, 376. [CrossRef]

25. Giri, C.; Long, J.; Tieszen, L. Mapping and monitoring Louisiana's mangroves in the aftermath of the 2010 Gulf of Mexico oil spill. J. Coast. Res. 2011, 27, 1059-1064. [CrossRef] 
26. Beever, L.; Beever, J.; Lewis, R.; Flynn, L.; Tattar, T.; Donley, E.; Neafsey, E. Identifying and Diagnosing Locations of Ongoing and Future Saltwater Wetland Loss: Mangrove Heart Attack; Charlotte Harbor National Estuary Program: Punta Gorda, FL, USA, 2016.

27. Groot, R.; Blignaut, J.; Ploeg, S. Benefits of Investing in Ecosystem Restoration. Conserv. Biol. 2013, 27, 1286-1293. [CrossRef] [PubMed]

(C) 2019 by the authors. Licensee MDPI, Basel, Switzerland. This article is an open access article distributed under the terms and conditions of the Creative Commons Attribution (CC BY) license (http://creativecommons.org/licenses/by/4.0/). 